\title{
Questions Regarding the Improvement of the Delay of Punishment under the Criminal Legislation of the Republic of Kazakhstan
}

\author{
Bahyt Baisekenovich Galiev ${ }^{1}$ \\ ${ }^{1}$ Federal State Institution of Higher Professional Education "Chelyabinsk State University" Kostanay branch \\ Kazakhstan, Kostanay, Kazakhstan \\ Correspondence: Bahyt Baisekenovich Galiev, Federal State Institution of Higher Professional Education \\ "Chelyabinsk State University" Kostanay branch Kazakhstan, 110000, Kostanay, Borodina Street, 168a, \\ Kazakhstan.
}

Received: November 20, $2014 \quad$ Accepted: December 12, $2014 \quad$ Online Published: February 25,2015
doi:10.5539/ass.v11n6p229

\begin{abstract}
Questions regarding the improvement of the delay of punishment under the criminal legislation of the Republic of Kazakhstan are considered in this article. Since obtaining validity, for the purpose of its improvement changes and additions were made systematically at present Criminal code of Kazakhstan. These legislative innovations entirely touched upon this type of release from punishment. However, despite the positive changes allowing expansion of a framework of this social and legal institution there are some questions regarding the attention at the legislative level.
\end{abstract}

Keywords: delay of punishment, pregnant women and women with juvenile children, imprisonment, men raising juveniles, surrender of child, termination of pregnancy, new crime

\section{Introduction}

It is common that a person who committed a crime in its majority is held criminally liable with the following imposing of penalty. Thus the aim of penalty is not retaliation concerning guilty, as its main destination consists in achieving its reformation or turning the last at least into the safe member of society. But the Law is wise and supposes that in some cases these purposes can be achieved by releasing of the sentenced person from punishment or further enduring the punishment.

One of types of release from punishment under the criminal legislation of the Republic of Kazakhstan of 1997 is the delay of punishment which originally extended only on the pregnant women or women with juvenile children. According to the fair remark by S. U. Skobelin, the places of imprisonment are poorly adapted for women and their children. A special physiological state of a woman during pregnancy, and also those problems which arise in connection with baby care, his education, can be hardly solved in the conditions of correctional facilities, which remain a serious obstacle in re-socialization of the condemned women and these complicate the achievement of the objectives of penalty in general (Skobelin, 2011, p. 57).

Therefore, undoubtedly, the delay of punishment is a measure of incentive character stimulating the condemned women to positive post-criminal behavior (Mikhaylov, 2009, p. 51).

\section{Methods of Research}

The methodology of research within the present article is made by a set of general scientific (system, dialectic, formally logical) and private scientific (comparatively legal, legalistic, historically legal) knowledge methods.

\section{Results}

The delay of punishment in the Criminal code currently in force under the Republic of Kazakhstan (further the criminal code of Kazakhstan) should be considered not only as realization of the humanity principle inherent in criminal law, but also as a legislative innovation because the former Criminal code of the Soviet Kazakh Socialist Republic, 1959 did not provide a similar type of release from punishment, unlike The Criminal code of the Russian Federation of 1960 where the last was entered by the Law of the Russian Federation of June 12, 1992. It is indisputable that delay of punishment of this category of women, the aspiration to social justice intertwines with care of future child and children that they already have, which in nation-wide level can be 
regarded as care of younger generation. This type of release from punishment in the criminal legislation of Kazakhstan is regulated by the Clause 72 of the criminal code of Kazakhstan and initially in the first edition was called "A delay of punishment to pregnant women and women with juvenile children".

However further this Clause was exposed to numerous changes as positive, so not absolutely successful from the point of view of legislative activity, and changes in its majority were concerned to part one of the Clause 72 of the criminal code of Kazakhstan where the bases of granting a delay to a certain category of persons and there were revealed terms of the delay.

So, the very first edition of the first part of the Clause 72 under the criminal code of Kazakhstan of 1997 said that "to the convinced pregnant women and women with children till eight years old except convinced to imprisonment for the term of over five years for heavy and especially serious crimes against the personality, the court can delay punishment respectively for a period of up to one year or when the child arrives the age of eight" (The Criminal code of the Republic of Kazakhstan, 1997).

Thereby, according to the quoted norm, the punishment to pregnant women by court could be delayed till one year and to the women with juvenile children-before the child arrives eight-year old age, and it is the right of court to grant the delay of punishment, but not its duty. Really the delay of punishment could be granted by court judgment, and at identification of pregnancy in later time and during the punishment.

But the legislator decided to expand a framework of using of this norm, and by the Law of the Republic of Kazakhstan of December 21, 2002 (the Law of the Republic of Kazakhstan No. 363, 2002) the changes were made in a disposition of the first part of the Clause 72 under the criminal code of Kazakhstan, owing to which the court could delay punishment to the pregnant woman till one year, and to the woman having the child under fourteen years-before arriving fourteen-year age. Undoubtedly, these changes had a positive character but we think that the differentiation of granting terms of a delay left by the legislator without a change (the pregnant woman till one year, and the woman having the child aged till fourteen years-before arriving fourteen-year age), contained certain shortcomings. The matter is that according to the second part of the Clause 72 of the criminal code of Kazakhstan if the convinced person refused the child, or continues to evade from his education, or to disturb public peace after the double written warning issued by the body exercising control of the convinced person, the court can cancel a punishment delay (therefore, cannot cancel) on representation of this body and to direct the condemned person for serving the punishment by court judgment. In case the court considered the allowed violations insufficient for cancellation of a delay, and the term of a year delay already expired by this time, the court had a need of extension of a delay of punishment.

Possibly, for this reason the disposition of the mentioned norm in 2007 underwent new changes and the convinced pregnant women and women with children aged till fourteen years except condemned to imprisonment for the term of over five years for heavy and especially serious crimes against the personality, the court could delay punishment serving respectively for a period of up to five years, but no more than before arriving fourteen-year age by (the Law of the Republic of Kazakhstan No. 240-III, 2007). At preservation of all other conditions on this type of release from punishment, the Law increased the minimum term of granting a delay of punishment to the convinced persons till five years, and having included in this category of persons, both pregnant women, and the women with juvenile children at preservation of the top limit-achievement of fourteen-year age by the child.

But the process of improvement of the considered norm continues. Two years later the legislator once again changed edition of the first part of the Clause 72 under the criminal code of Kazakhstan, without new information in it, owing to unclear logic, having returned as a matter of fact, on former positions from which contents followed that to the condemned pregnant women the court can delay punishment till one year. To the convinced women having juvenile children, the court can delay an execution of the punishment before arriving fourteen-year age by the child. But throughout evolution of the called norm, invariable was a ban: to the pregnant women and women having juvenile children, convinced to imprisonment for the term of over five years for heavy or especially serious crimes against the personality, the delay of punishment isn't granted (the Law of the Republic of Kazakhstan No. 227-IV, 2009).

Meanwhile, the name and edition of the mentioned Clause unambiguously testified the impossibility of its use to the male, means to the child's father (juvenile children), at least it was also allocated with the same privileges and the rights, as the child's mother, according to the legislation, for example, at her death, deprivation of the parental rights, etc. It wasn't coordinated with the constitutional provision on equality before the law and court, including in questions of protection, irrespective of a gender.

It is necessary to pay tribute that according to the Law of the Republic of Kazakhstan of January 18, 2011. (The 
law of the Republic of Kazakhstan No. 393-IV, 2011) this inequality was overcome and limits of application of the considered Clause among the persons began to extend, besides the pregnant women and women with juvenile children, and on men alone raising juvenile children. Then the first part of the Clause 72 under the criminal code of Kazakhstan was again changed by the Law of the Republic of Kazakhstan No. 490-IV of November 9, 2011 according to which for women with juvenile children and men alone raising juvenile children, the court can delay punishment till five years, but no more than before arriving fourteen-year age by the child, at preservation of a year of a delay to pregnant women (The law of the Republic of Kazakhstan No. 490-IV, 2011).

Thus, the first part of Clause 72 of the criminal code of Kazakhstan looks as follows:

Clause 72 "Delay of Punishment to the Pregnant Women and Women with Juvenile Children, and to the Men Alone Raising Juvenile Children".

The first part: "To the convinced pregnant women the court can delay punishment till one year. To the convinced women with juvenile children and the men alone raising juvenile children, the court can delay an execution of the punishment till five years, but no more than before the child arrives fourteen-year age. To the pregnant women and women having juvenile children and the men alone raising juvenile children, convinced to imprisonment for the term of over five years for heavy or especially serious crimes against the personality, the delay of punishment isn't granted".

Respectively, the name of the Clause 72 of the criminal code of Kazakhstan gained more bulky character because it had not subjected to reductions for an obvious reason as in the Criminal law of RK there was the Clause 74 under the name "Release from punishment and delay of punishment owing to unexpected circumstances" where it was about absolutely other bases of granting a delay of punishment.

Special thing about the legal nature of a delay of punishment to the pregnant women and women with juvenile children and to the men alone raising juvenile children is the existence of characteristics such as nominal conviction, when it is applied by court under the guilty verdict, and the release on parole when the convinced person already serves the sentence imposed by court.

It is obvious that under a delay of punishment to the pregnant women and women with juvenile children, and the men alone raising juvenile children you should understand the release of the convinced person from the sentence imposed by court or from its further serving under certain conditions.

Proceeding from the name and sense of the studied norm, the basis of application of the considered type of release from punishment is pregnancy of the woman or presence of juvenile children, and men bringing up juvenile children alone. Existence of pregnancy presence of children is verified by medical certification. By The Criminal law of the Republic of Kazakhstan juvenile children are the children under 14 years.

At the same time a very essential collision was found. The legislator both in the name and text of Clause 72 of the criminal code of Kazakhstan should point out not "juvenile children", but "the juvenile child" as literal interpretation of norm allows to draw to a conclusion that the delay of punishment is applicable only to the women and men having more than one juvenile child on education. There were made reasonable judgments that for granting a delay of punishment to the woman (and the man-the note of the author) it is enough to have one child under 14 years (Petrova, 2005, p. 19). Besides, delay of the punishment, after the changes, depending on the basis, started to have as it was already earlier, the differentiated character-to pregnant women till one year, to the women with juvenile children and the men alone raising juvenile children-till five years, but no more than before a child arrives fourteen-year age.

We consider that it would be more preferable to return to earlier edition of the first part of Clause 72 of the criminal code of Kazakhstan entered by the Law of the Republic of Kazakhstan of December 10, 2009 No. 227-IV "About modification and additions in Criminal, Criminal procedure and Civil procedural codes of the Republic of Kazakhstan concerning improvement of judicial system" where the delay of a punishment deadline was mentioned-"before the child arrives fourteen-year age", having excluded intermediate "till one year" and "till five years".

\section{Discussion}

Application of a delay is tabooed to the category of persons listed in the first part of the Clause 72 of the criminal code of Kazakhstan in case they are condemned to imprisonment for the term of over five years for heavy or especially serious crimes against the personality.

The law doesn't explain, what circle of crimes should be carried to crimes against the personality: or these are the crimes where the personality acts as exclusively main direct object of encroachment (for example, at murder), or 
at encroachment of other direct object, the personality is also exposed to illegal influence, but thus has the status of additional direct object (for example, that takes place at assault).

The law doesn't explain, what circle of crimes should be referred to crimes against the personality: or without philosophizing concerning a circle of heavy and especially serious crimes against the personality, there is a wish to note that most of the authors fairly believe that it is necessary to carry crimes where the personality acts not only as the basic, but also additional direct object of encroachment to the considered group of crimes. Sharing the given point of view, we, nevertheless, consider that for uniform interpretation of the norm stated in the first part of the Clause 72 of the criminal code of Kazakhstan it should be formulated more specifically or to supply the Clause 72 of the criminal code of Kazakhstan with the note opening concept of heavy and especially serious crime against the personality, having referred to them not only the crimes provided by Chapter of the first Special part of the criminal code of Kazakhstan "Crimes against the personality", but also crimes in which the personality acts as obligatory additional object of encroachment.

From this legislative ban on delay of punishment follows that the court can apply the standard of the Clause 72 of the criminal code of Kazakhstan, if:

a) The person is condemned for heavy and especially serious crimes, but not directed against the personality;

b) The person is condemned for the heavy and especially serious crimes directed against the personality, but punishment for them doesn't exceed five years of imprisonment;

c) The person is condemned for all crimes of small or average gravity.

At the same time, it would be necessary to establish a ban on using a delay of punishment to the persons deprived of the parental rights, leading an antisocial life, having alcoholism, drug addiction and toxic mania. Probably, it is presumed in law-enforcement activity, but considering social and legal importance of this question, it had to find exhaustive reflection in the law.

Besides, it is necessary to mention one condition which isn't defined in the Criminal law, but it is regulated by the norms of the Criminal and executive right of the Republic of Kazakhstan. According to the third part of the Clause 171 of the Criminal code of RK which establishes an order of granting a delay of punishment concerning the mentioned persons "the authority of correctional institution directs to court the conception of using a delay of punishment to the condemned person or his corresponding petition.

The characteristic of the condemned person, the inspection report about the domestic conditions of the relatives who agreed to accept the condemned person and the child, to provide them housing and to create necessary conditions for accommodation, made by probation department, medical certification about pregnancy or the certificate on presence of the child, and also a personal record of the condemned person is attached to them". From this regulation follows the conclusion: if a family or relatives of the condemned person with the child didn't express a consent to cohabitation, and the person has no opportunities to provide appropriate conditions for education of the child, so the judgment about granting a delay has to be negative as current situation won't promote achievement of the objectives of punishment.

Not analogous, but similar norms regulating the delay of punishment are contained in the Clause 82 of the Criminal Code of the Russian Federation and, according to I. M. Lukyanova, the criminal legislation has to regulate the concept, the purposes, the bases, conditions of application and cancellation of delay of punishment. In its turn, questions on control of behavior of women (and men already-the note of the author), their legal status, means applied at realization of delay, a legal status of condemned and responsibility for evasion from this measure have to be regulated by standards of the criminal and executive legislation. Procedural questions of appointment, changes made by court about conditions of realization and termination of a delay of punishment need to be fixed in the Russian Federation Code of Criminal Procedure (Lukyanova, 2009, p. 30).

The legislator ignored a question concerning the types of punishment when the delay of punishment to the condemned is possible. Opinions of lawyers on this question were reduced to two main positions: a) in respect to a release from one type of punishment-imprisonment; b) in respect to imprisonment it is necessary to add engaging to public works, correctional works and restriction of freedom. The question is not about the arrest as this type of punishment is excluded from the Criminal Code of Kazakhstan.

According to authors of one of the issues on criminal law of the Russian Federation, the delay is applied only to the women condemned to imprisonment because the duration of a trial period is estimated before the child arrives 14-year age irrespective of the personality of a guilty, the character and degree of public danger of deeds (except condemned for the term of over five years for heavy and especially serious crimes against the personality, etc.). Such trial period is incompatible with a delay from other, less severe and not so long punishments. 
Therefore the opinion of the authors about the delay of punishment seems doubtful (Inogamova-Hegay et al., 2008, p. 464).

Others believe that the delay is addressed to the women condemned to penalties connected with isolation from society (arrest, imprisonment for a certain period and maintenance in disciplinary military unit as this measure is aimed at granting to a mother an opportunity to bring up the child. Condemnation to punishments without isolation from society (correctional works, obligatory works, etc.) doesn't prevent mother to bring up the child (Markets \& Mikhaylov, 2001, p. 99).

Other point of view comes down to the fact that the Criminal code doesn't link the considered institute with a certain type of punishment (Ignatov \& Krasikov, 2000, p. 500).

V. V. Maltsev also allows the use of delay at any punishment and even penalty, as the delay of penalty quite often can appear more favorable, than a delay of other types of punishment (Maltsev, 2003, p. 196).

It seems it would be necessary to think over the matter selectively. First of all, the delay of punishment can be granted to a condemned person by the court both at purpose of punishment, and during the service of sentence. By the sentence to the pregnant women and women having juvenile children under the law, the question is about imprisonment, as public works (Part 3, Clause 42 of the criminal code of Kazakhstan) aren't appointed to the pregnant women and women having children under three years, and correctional works (Part 3, Clause 43 of the criminal code of Kazakhstan) in particular, can't be assigned to people, recognized disable, not having permanent job (The Criminal code of the Republic of Kazakhstan., 2014, p. 29) where it is quite possible to rank women with big terms of pregnancy or that having babies. Therefore, the sentence in the form of correctional works or public works can be appointed and delayed only to the women having children at dependence over three years old. As for pregnant women, according to Part 8, Clause 169 under the Penal Code of the Russian Federation, in case a convinced woman is pregnant and condemned to punishment in the form of attraction to public works, correctional works or restriction of freedom, the chief of the establishment or body executing punishment brings in court the idea about the delay of punishment from the date of granting a maternity leave (The Criminal code of the Republic of Kazakhstan, 2014, p. 65).

It should be noted that in the first part of the Clause 452 under the Criminal code of the Republic of Kazakhstan which regulates a delay of sentence, besides attraction to public works, corrective works, imprisonment, also restriction of freedom is mentioned (the Criminal code of the Republic of Kazakhstan, 2014, p. 182). Though the Criminal law of the Republic of Kazakhstan doesn't set any restrictions concerning a delay of punishment in the form of restriction of freedom, but considering its essential liberalization in the criminal legislation, in our opinion granting such delay is unjustified. Besides, the argument given above that condemnation to punishments without isolation from society deserves attention (correctional works, obligatory works, etc.) doesn't prevent mother to bring up the child. We consider, it fully belongs to such type of punishment as restriction of freedom, and it would be expedient to establish a direct ban in Clause 72 of the criminal code of Kazakhstan on granting a delay of punishment in the form of restriction of freedom.

Additional punishments dropped out of a field of vision of the legislator for the unclear reason and here two versions of their decision in the law are possible: the court can also delay their real execution along with the basic, or they have to be executed in the period of a delay. The first variant is preferable to us and it would be preferable to meet a special instruction in the first part of Clause 72 of the criminal code of Kazakhstan that "in these cases the court can delay execution and additional punishments".

At the same time, to the man, who is the only parent of the juvenile child, the delay of serving of punishment can be granted both at purpose of punishment, and during the sentence, and in the form of imprisonment, attraction to public works and correctional works, besides as it was told above, limitation of freedom.

Also the third part of Clause 72 of the criminal code of Kazakhstan demands concrete interpretation. According to it after the termination of delay of punishment or in case of death of the child, or in case of pregnancy interruption, the court, depending on behavior of the condemned person, can accept one of three alternative decisions: 1) to release it from sentence; 2) to replace the imposed sentence with mild sentencing; 3 ) to send the condemned person to the relevant institution for service of sentence.

As we see, there is no accurate regulation in the law, in what cases the court acquit the condemned person of sentence service or its remained part and in what cases replaces with mild type of punishment or owing to some reasons directs the condemned person in corresponding establishments for sentence service, and all conditions have alternative character. Thereby, the solution of similar questions is found in full competence of court.

It seems that the court can make the decision on release of the condemned person from punishment after delay 
term in case of appropriate education and care of the child, law-abiding behavior of the person that would prove his rehabilitation.

In case when the condemned person in general satisfied terms of a delay and, in fact, followed a way of rehabilitation, but there were remarks from the government body exercising control of his behavior, but the question of cancellation of a delay didn't arise, upon termination of the granted delay it is more expedient to court to raise a question of replacement of the imposed sentence or unexpired its part with mild type of punishment.

Respectively, if the behavior of the condemned person doesn't give the grounds to consider him improved or become on the way of rehabilitation and there is a danger of recurrence of crimes from its turn, the court will be compelled to send the condemned person to the relevant institution for punishment serving.

In case of death of the child because of inappropriate care or deliberate interruption of pregnancy, without medical indications before the delay, the court on the basis of the materials presented by criminal and executive inspection, has the right to cancel a delay and to send the condemned person for sentence service to the place designated according to a court verdict. Therefore it would be expedient to transfer such circumstances to the second part of the Clause 72 of the criminal code of Kazakhstan where it is told about the bases of cancellation of the delay granted by court.

At the same time, if the condemned person before the death of the child honestly fulfilled the duties on education and its care and the death occurred due to other reasons (for example, pathology of the newborn, a serious illness), court as it seems to us, has to exempt the condemned person from sentence service. This results from the fact that loss of the child, especially for the woman, is in most cases perceived as the personal tragedy and as stricter penalty, than serving of the sentence imposed by court, even if connected with imprisonment. If interruption of pregnancy was a consequence of any pathology or accident, or because of medical indications, the court, in our opinion, should replace the imposed sentence or the remained unexpired part of punishment by mild type of punishment.

Cancellation of a delay of punishment lead to the following: if the condemned person refused the child, or continues to evade from education of the child, or to disturb public peace after the double written warning issued by the body exercising control of the condemned person, in this case the court on representation of this body can cancel a delay and direct the condemned person for punishment serving (Part 2, Clause 72 of the criminal code of Kazakhstan).

Thus, this norm, with all evidence, has a dispositive character. It seems if the condemned person refused the child or continues to evade from his education, or to disturb public peace, in spite of preventions of probation department, the court not "can't", but "has to" cancel a delay, having protected thereby the interests of the child .The delay in relation to the child loses meaning because it doesn't receive due care and education, and the condemned person, on the contrary, receives unjustified indulgence.

Besides, the mentioned norm, in our opinion, suffers from a certain problem. In particular, the condemned person can fulfill duties on upbringing of the child, but thus lead a chaotic life, abuse alcoholic drinks, use drugs or psychotropic substances. At last, the condemned person can simply disappear from residence in this connection there will be a need to issue this notice. According to T. Sharipov, disappearance of the condemned woman from the place of residence as the basis for cancellation of a delay has independent value in case when it isn't connected with refusal of mother of the child and evasion of education. In particular, he refers to the special literature devoted to penal institutions where it is noted that there are situations when women disappear together with the child, changing a residence and without informing the probation department. Thus the woman doesn't evade from education of children, and intends to avoid control from probation department (Sharipov, 2008, pp. 20-21). These factors also should be considered in the law.

By the way, regarding the third part of the Clause 172 of the Criminal code of RK, it is told, "in case the condemned person ... disappeared ... the probation department in their communities brings in court the idea of cancellation of delay of punishment and the direction of the condemned person for the sentence service imposed by court ...". We believe, this basis of cancellation of a delay, the condemned person interfaced to running away, first of all has to be recorded in detail in the text of the criminal law that is regarding the second Clause 72 of the criminal code of Kazakhstan.

At the same time Kazakh legislator didn't resolve the situation when before a child arrives 14-year age expires the term equal to the term of punishment which serving was delayed.

The special norm devoted to this circumstance was included in similar institution by the Russian legislator (Part 
4. Clause 82 of the criminal code of the Russian Federation) (The Criminal code of the Russian Federation, 2014, p. 31) according to which if the body exercising control of behavior under the condemned person, comes to a conclusion that condemned observes conditions of a delay and its rehabilitation, due to these facts the court can make the decision on reduction of terms of a delay of punishment and on release of the punishment to the condemned or the rest of punishment with cancellation of a criminal record. Absence of such norm during the existence of institution of a delay in the Russian legislation was regarded by I. A. Petrova (2005, p. 148) and P. V. Teplyashin, Umetbayev, \& Sitdikov (2007, p. 115) as very serious omission. We believe the similar norm should be included and in the Clause 72 of the criminal code of the Republic of Kazakhstan.

Regarding the fourth part of the Clause 72 of the criminal code of Kazakhstan the rules of sentence in case of commission by the condemned person of a new crime are prescribed. Though the law tells nothing, but the sentence service delay, undoubtedly, is cancelled, otherwise it is impossible to impose sentence on set of punishments. According to the logic of the legislator, it doesn't matter, to what category the new crime will belong and with what form of fault it is made.

At the same time, the legislator ignored a very important question and which is pointed in the article by Yu. Skobelin (2011, p. 60). As the practice shows, it is frequent after court judgment or in the course of the sentence service imposed by court it is found out that the condemned person is guilty of the crime committed by it before court judgment on the first case. We consider that this situation has to get the corresponding permission in the law for this reason to amplify the Clause 72 of the criminal code of Kazakhstan with the fifth part in the following edition.

The fifth Part: "In case after court judgment with a delay of punishment or in the period of a delay of punishment establishes that the condemned person is guilty also of other crime committed by it before court judgment on the first case, the court cancels a delay of punishment and imposes sentence to the condemned person on set of sentences".

Conclusion

Thus, the author studied evolution of delay of punishment in the legislation of the Republic of Kazakhstan from the moment of enactment of the Criminal code since January 1, 1997. The frequency of the changes made to it showed the desire of the legislator to improve this institution because the last has not only legal, but also social value and at the heart it has a humanistic character. It is necessary to pay tribute, in a certain measure it managed to do this. Unfortunately, changes had not always consecutive and successful character and therefore standards of Clause 72 of the criminal code of Kazakhstan demand further improvement.

\section{References}

Criminal code of the Republic of Kazakhstan. (n. d.). Almaty: Жеті zharғы.

Ignatov, A., \& Krasikov, Y. (2000). Criminal justice of Russia. The manual for higher education institutions. In 2 parts. P.1. General part. Moscow: Norma.

Inogamovoy-Hegay, L., Komissarov, V., \& Raroga, A. (2008). Russian criminal law: Studies in 2 parts. P.1. The general part. Under the editorship of $2^{\text {nd }}$ ed., arranged and enlarged. Moscow: TK Velbi, Prospectus.

Law of the Russian Federation "About modification and additions in the correctional labor code of the Russian Soviet Federated Socialist Republic, the Criminal code of the Russian Soviet Federated Socialist Republic and the Code of criminal procedure of the Russian Soviet Federated Socialist Republic". (1992, June 12). Sheets of Congress and the Supreme Council of the Russian Federation, No. 29, Cl. 1687.

Lukyanova, I. (2009). Branch accessory of norms on a delay of punishment to the pregnant women and women having juvenile children. Bulletin of the Vladimir legal institute, 2(11).

Maltsev, V. (2003). Problems of release from criminal liability and punishment in criminal law. Volgograd.

Markets, R., \& Mikhaylov, K. (2001). Release from criminal liability and punishment: Manual. Chelyabinsk.

Mikhaylov, K. (2009). Delay of punishment. Legality, 2.

Petrova, I. (2005). Delay of punishment to the pregnant women and women having juvenile children, Synopsis of a thesis. Moscow.

Petrova, I. (2005). Delay of punishment to women in the criminal legislation of Russia. Under the editorship of A. V. Kladkov. Vologda.

Sharipov, T. (2008). Legal consequences of the expiration of a delay of punishment of pregnant women to the women and women having juvenile children. Russian investigator, 11 . 
Skobelin, S. (2011). Administration of the delay of punishment. Criminal law, 4, 57.

Teplyashin, P., Umetbayev, T., \& Sitdikov, M. (2007). Institute of a delay of punishment needs improvement. Collection of materials of the International scientific and practical conference. P.1. Actual problems of fight against crime in the Siberian region. Krasnoyarsk: Siberian Ministry of Internal Affairs legal institute of Russia.

The Criminal and executive code of the Republic of Kazakhstan. (2014). Almaty: Lawyer.

The Criminal code of the Republic of Kazakhstan. (2014). Almaty: Norma-K.

The Criminal code of the Russian Federation. (2014). Moscow: Omega-L.

The Criminal procedure code of the Republic of Kazakhstan. (2014). Almaty: Lawyer.

The law of the Republic of Kazakhstan No. 227-IV "About modification and additions in Criminal, Criminal procedure and Civil procedural codes of the Republic of Kazakhstan concerning improvement of judicial system". (2009, December 10). Sheets of Parliament of the Republic of Kazakhstan, No. 6-7, Cl. 32; No. 13-14, Cl. 63; No. 15-16, Cl. 71, 73, 75; No. 17, Cl. 82, 83.

The law of the Republic of Kazakhstan No. 240-III "About modification and additions in some acts of the Republic of Kazakhstan concerning criminal and executive system". (2007, March 26). Sheets of Parliament of the Republic of Kazakhstan, No. 5-6, Cl. 40.

The law of the Republic of Kazakhstan No. 363-II "About modification and additions in Criminal, Criminal procedure and Criminal codes of the Republic of Kazakhstan". (2002, December 21). Sheets of Parliament of the Republic of Kazakhstan, No. 4, Cl. 32, 33; No. 17, Cl. 155.

The law of the Republic of Kazakhstan No. 393-IV "About Modification and Additions in Some Acts of the Republic of Kazakhstan concerning a Further Humanization of the Criminal Legislation and Strengthening of Guarantees of Legality in Criminal Trial". (2011, January 18). Sheets of Parliament of the Republic of Kazakhstan, No. 2 (2579), Cl. 19.

The law of the Republic of Kazakhstan No. 490-IV. "About modification and additions in some acts of the Republic of Kazakhstan concerning improvement of law-enforcement activity and a further humanization of the criminal legislation". (2011, November 9). Sheets of Parliament of the Republic of Kazakhstan, No. 1, Cl. 9; No. 2, Cl. 19, 28.

\section{Copyrights}

Copyright for this article is retained by the author(s), with first publication rights granted to the journal.

This is an open-access article distributed under the terms and conditions of the Creative Commons Attribution license (http://creativecommons.org/licenses/by/3.0/). 